\title{
TÉCNICAS DE QUEBRA DE DORMÊNCIA E ESTUDO DE SUBSTRATOS ORGÂNICOS PARA PRODUÇÃO DE MUDAS DE LEUCENA
}

\section{TECHNIQUES TO BREAK DORMANCY AND STUDY OF ORGANIC SUBSTRATES FOR PRODUCTION OF LEUCENA SEEDLINGS}

\author{
Ticiana Vasques Araujo ${ }^{1}$ \\ Walderez Moreira Joaquim² \\ Paulo Roxo Barja $^{3}$
}

RESUMO: O objetivo deste trabalho foi o de avaliar o desenvolvimento de técnicas apropriadas para a produção de mudas de Leucaena leucocephala (Lam.) de Wit., através de técnicas já consagradas da quebra do estado de dormência da semente e a partir da técnica mais eficiente, verificou-se a influência de substratos orgânicos. $A$ planta estudada foi escolhida devido sua utilização como excelente fonte de proteína bruta e de forragem de boa qualidade para animais. Foram utilizados treze tratamentos para quebra de dormência: grupo sem tratamento, imersão em água na temperatura ambiente por 12, 24 e 36 horas, imersão em água quente a $80^{\circ} \mathrm{C}$ por 5,10 e 15 minutos, choque térmico em $100^{\circ} \mathrm{C}$, imersão em ácido sulfúrico por 6 e 10 segundos, imersão em soda cáustica por 6 e 10 segundos e escarificação com lima de metal. As plântulas dos dois melhores tratamentos de quebra de dormência, imersão em água quente a $80^{\circ} \mathrm{C}$ por 5 minutos e escarificação com lima de metal, foram testadas em quatro substratos diferentes: grupo controle, grupo 2 de esterco de carneiro, grupo 3 de esterco de ave e grupo 4 de esterco de gado. Constatou-se que para a adubação orgânica o tratamento mais eficaz foi à utilização do substrato com esterco de ave.

Palavras-chave: Leucaena leucocephala; germinação de sementes; plântulas.

ABSTRACT: The objective of this study was to evaluate the development and appropriate techniques for the production of Leucaena leucocephala (Lam.) de Wit., seedlings. Already established techniques to break the seed's dormant state were tested. Then the most effective techniques were used to test the influence of organic substrates. The studied plant was chosen because of its use as an excellent source of protein and good quality forage for animals. Thirteen different treatments were used to break dormancy: group without treatment; immersion in water at room temperature for 12,24 , and $36 \mathrm{~h}$, immersion in hot water at $80^{\circ} \mathrm{C}$ for 5,10 , and 15 min, thermal shock at $100^{\circ} \mathrm{C}$; immersion in sulfuric acid for 6 and 10 seconds; immersion in caustic soda for 6 and 10 seconds; and scarification with a metal file. The two best treatments to break dormancy of the seedings, which were the immersion in hot water at $80^{\circ} \mathrm{C}$ for $5 \mathrm{~min}$ and scarification with the metal file, were tested in four different substrates: control group, group 2 - sheep manure, group 3 - poultry manure, and group 4 - cattle manure. The most effective organic fertilizer was the the substrate with poultry manure.

Keywords: Leucaena leucocephala; germination of seeds; seedlings.

\footnotetext{
${ }^{1}$ Graduada em Ciências Biológicas - Universidade do Vale do Paraíba - Univap. E-mail: ticianavasques@uol.com.br.

2 Doutora em Ciências Biológicas - Botânica pela Universidade Estadual Paulista Julio de Mesquita Filho - UNESP e Professor Titular da Univap. E-mail: wal@univap.br.

${ }^{3}$ Doutor em Física - Universidade Estadual de Campinas - Unicamp e Professor Titular da Univap. E-mail: barja@univap.br.
} 


\section{INTRODUÇÃO}

A leucena (Leucaena leucocephala (Lam.) de Wit.) é uma planta utilizada no reflorestamento de áreas degradadas, como adubação verde de pastagens, na alimentação animal, sombreamento para animais e obtenção de madeira para lenha. É importante fonte de proteína bruta e forragem de boa qualidade, além de possuir grande quantidade de sementes viáveis, o que facilita sua propagação em larga escala (PRATES et al., 2000).

Leucaena leucocephala é uma leguminosa de ciclo longo de rápida dispersão, com uma habilidade de crescer em solos de baixa fertilidade, porém é exigente em solos mal drenados ou muito ácidos, pois estes ambientes prejudicam a disponibilização de nutrientes (SOUSA, 2005). Seu desenvolvimento pode ser interferido quando o solo apresenta alto teor de alumínio e deficiência de cálcio, responsáveis pela nodulação, assim como o magnésio, molibdênio, fósforo e zinco, necessários no início de crescimento da planta, como também na formação de uma raiz mais profunda (LIMA; EVANGELISTA, 2006).

Estudos realizados por El-Bedawy et al. (1999), demonstraram que a cobertura com solo de leucena apresenta-se como medida de controle de plantas daninhas, devido à presença de um aleloquímicos na parte aérea da planta, denominado mimosina (aminoácido).

Prates et al. (2000) observaram que o extrato aquoso de Leucaena leucocephala obtido com água quente, quando aplicado em papel-germiteste, provoca efeito sobre o crescimento da raiz seminal, mas não causa efeito sobre a parte aérea das plantas e nas sementes de milho, tanto o comprimento da radícula como da parte aérea são sensíveis ao extrato, indicando que esses efeitos estão relacionados com a mimosina.

Souza-Filho et al. (1997) observaram o extrato aquoso da parte aérea de leucena e constataram a inibição da germinação e do comprimento da radícula de desmódio (Desmodium adscendens), guanxuma (Sida rhombifolia) e assa-peixe (Vernonia polyanthes), indicando que esses efeitos estão relacionados com a mimosina.

Sementes consideradas viáveis e sob condições adequadas algumas vezes deixam de germinar; tais sementes são denominadas dormentes, e requerem tratamentos especiais como imersão em água, escarificação ou imersão em produtos químicos para que ocorra a germinação, este processo é denominado quebra de dormência (CARVALHO; NAKAGAWA 2000). Deminicis et al. (2008) constataram que a técnica de escarificação mecânica promovida pela imersão de sementes em água fervente $\left(100^{\circ} \mathrm{C}\right)$ durante 10 minutos, foi a mais eficaz na superação da dormência das sementes de leucena.

Avaliando a diferença entre os métodos de imersão em água e ácido sulfúrico $\left(\mathrm{H}_{2} \mathrm{SO}_{4}\right)$, Souza et al. (2007) concluíram que o tratamento mais eficiente foi $\mathrm{H}_{2} \mathrm{SO}_{4}$ concentrado por cinco minutos.

Oliveira e Medeiros Filho (2007) relatam que sementes de leucena submetidas à semeadura sem quebra de dormência, apresentaram um índice de germinação inferior a 50\%, tornando-se inviável a produção de mudas e confirmando a necessidade da quebra de dormência das sementes dessa espécie.

A composição do substrato pode afetar a germinação e o desenvolvimento das 
plantas jovens de modo que sua escolha deve ser realizada em função das exigências da semente em relação ao seu tamanho e formato. As funções básicas do substrato proporcionam a sustentação da planta, fornecimento de nutrientes, retenção de água e oxigênio, trocas catiônicas, boa aeração e drenagem, promovendo condições ideais para o crescimento e desenvolvimento das mudas (MENDES et al., 2006).

Lucena et al. (2006) verificaram que o estrume de galinha favorece significativamente 0 desenvolvimento das plântulas de leucena quando comparadas à germinação das sementes.

Lucena et al. (2004) verificaram a influência dos substratos húmus de minhoca, esterco de ave e esterco de gado nas sementes e plântulas de Leucaena leucocephala (Lam.) de Wit., constatando que as sementes em substrato contendo húmus de minhoca apresentaram aumento da emergência e o substrato contendo esterco de ave promoveu melhor desenvolvimento das plântulas. Os autores concluíram que o tipo do substrato influi na germinação e vigor inicial das sementes estudadas.

O presente trabalho tem como objetivo avaliar técnicas já consagradas para o desenvolvimento de técnicas de quebra de dormência de Leucaena leucocephala (Lam.) de Wit., e a partir da técnica mais eficiente, verificar a influência de substratos orgânicos na produção de mudas desta espécie, relevante para reflorestamento e banco de proteínas para ruminantes.

\section{MATERIAL E MÉTODOS}

Os experimentos foram conduzidos na casa de vegetação da Universidade do Vale do Paraíba (UNIVAP) em São José dos Campos, São Paulo. As sementes foram coletadas da árvore de Leucaena leucocephala a pleno sol, próximo à casa de vegetação no mês de setembro de 2011 e armazenadas em envelopes de papel durante 30 dias, conforme metodologia empregada por (MALUF; PISCIOTTANOEREIO, 2005).

No experimento que analisou as técnicas de quebra de dormência, as sementes foram submetidas a 13 tratamentos tradicionalmente empregados para quebra de dormência, inteiramente casualizados (Tabela 1); cada tratamento foi aplicado a quatro repetições com 24 sementes cada, totalizando 96 sementes por tratamento.

Tabela 1 - Grupos de tratamentos a que as sementes de Leucaena leucocephala foram submetidas

\begin{tabular}{ll}
\hline & Tratamentos \\
\hline T1 & Grupo testemunha (sem tratamento) \\
T2 & Imersão em água em temperatura ambiente por 12 horas \\
T3 & Imersão em água em temperatura ambiente por 24 horas \\
T4 & Imersão em água em temperatura ambiente por 36 horas \\
T5 & Imersão em água quente na temperatura de $80^{\circ} \mathrm{C}$ por 5 minutos \\
T6 & Imersão em água quente na temperatura de $80^{\circ} \mathrm{C}$ por 10 minutos \\
T7 & Imersão em água quente na temperatura de $80^{\circ} \mathrm{C}$ por 15 minutos \\
T8 & Imersão em água na temperatura de $100^{\circ} \mathrm{C}$ seguida de imersão em água na \\
& temperatura ambiente $(\mathrm{Choque}$ térmico) \\
T9 & Imersão em ácido sulfúrico $\left(\mathrm{H}_{2} \mathrm{SO}_{4}\right)$ por 6 segundos \\
T10 & Imersão em ácido sulfúrico $\left(\mathrm{H}_{2} \mathrm{SO}_{4}\right)$ por 10 segundos \\
T11 & Imersão em soda caustica $(\mathrm{NaOH})$ por 6 segundo \\
T12 & Imersão em soda caustica $(\mathrm{NaOH})$ por 10 segundos \\
T13 & Escarificação com lima de metal \\
\hline
\end{tabular}


As sementes foram imersas em ácido sulfúrico concentrado (pureza de $80 \%$ ) e em soda cáustica (80\%), revolvidas com bastão de vidro para uniformizar a sua ação nos tempos de 6 e 10 segundos. Em seguida, foram lavadas em água corrente por 10 minutos para remover o ácido sulfúrico e a soda cáustica, e posteriormente semeadas em bandejas de isopor com 120 células, contendo como substrato areia e húmus na proporção de 4:1, segundo metodologia proposta por Teles et al. (2000).

Os parâmetros analisados foram porcentagem de emergência (E\%) e índice de velocidade de emergência (IVE). Tanto a contagem das sementes germinadas como a análise dos parâmetros de interesse foram realizadas diariamente durante 15 dias, sendo posteriormente calculado o índice de velocidade de emergência (IVE) seguindo a metodologia de Nakagawa (1999), que utiliza a fórmula proposta por (NAGUIRE, 1962):

$\mathrm{IVE}=\mathrm{E} 1 / \mathrm{N} 1+\mathrm{E} 2 / \mathrm{N} 2+\ldots \mathrm{En} / \mathrm{Nn}$,

Onde: En é o número de plântulas germinadas da primeira à última contagem e $\mathrm{Nn}$, o número de dias da semeadura da primeira à última contagem, no décimo quinto dia.

O segundo experimento constou da avaliação dos substratos esterco de ave, carneiro e gado em plântulas de leucena obtidas a partir dos seguintes tratamentos para quebra de dormência: i) imersão em água quente a $80^{\circ} \mathrm{C}$ por 5 minutos; e ii) escarificação com lima de metal. O delineamento experimental foi inteiramente casualizado, utilizando-se 80 plântulas do tratamento T5 (água quente a $80^{\circ}$ por 5 minutos) e 80 plântulas do tratamento T13 (escarificação com lima de metal). Cada tratamento constou de 5 repetições com 16 plantas.

Para melhor desenvolvimento das plântulas as mesmas foram plantadas separadamente em bandejas de isopor, contendo como substrato areia e húmus na proporção de 4:1 por um período de 15 dias. Posteriormente, as plântulas originadas de sementes submetidas ao tratamento T5 (água quente a $80^{\circ} \mathrm{C}$ por 5 minutos) foram denominadas de "grupo A" e plântulas originadas do tratamento T13 (escarificação com lima de metal) o "grupo E". As 85 plântulas de cada grupo foram submetidas a quatro tratamentos inteiramente casualizados; plantadas em tubetes de 10 $\mathrm{cm}$ com os seguintes substratos: $1=$ controle $(50 \%$ terra, $50 \%$ serragem $), 2=$ esterco de carneiro (40\% terra, $40 \%$ serragem e $20 \%$ esterco de carneiro), $3=$ esterco de ave (40\% terra, $40 \%$ serragem e $20 \%$ esterco de ave) e $4=$ esterco de gado ( $40 \%$ terra, $40 \%$ serragem e $20 \%$ esterco de gado).

As variáveis analisadas foram altura, emissão dos folíolos, peso de matéria fresca e seca total (em gramas) de cada órgão individualmente, em intervalos de 14 dias durante 4 meses, de acordo com Benicasa (2004). As raízes, caules e folhas (pecíolo e limbo) foram acondicionados em saco de papel e mantidos em estufa a $60^{\circ} \mathrm{C}$ por três dias, até estabilização do peso da matéria seca. A avaliação química dos substratos foram realizadas através da análise de solo pelo método de resina segundo fórmula proposta por Van Raij et al. (2001), realizada no Departamento de Solos da Universidade de Taubaté (UNITAU) em Taubaté, São Paulo. A avaliação física analisada pelo 
método de resina não pôde ser realizada devido à alta quantidade de matéria orgânica, além da pouca quantidade de solo com argila, slite e areia utilizado nos tratamentos. Como o segundo experimento consistiu do teste de 2 tratamentos de quebra de dormência e 4 substratos, foi efetuada a análise estatística dos parâmetros por ANOVA (análise de variância), seguida de teste de comparação de médias por Tukey, adotando-se o nível de significância de $5 \%$ de probabilidade.

\section{RESULTADOS E DISCUSSÃO}

Após a análise das taxas de germinação (em porcentagem), os maiores valores encontrados para quebra de dormência obtidos para os tratamentos $\mathrm{T} 13$ (91\% de sementes germinadas) e T5 $(89,5 \%)$. O tratamento $\mathrm{T} 8 \mathrm{vem}$ em seguida, com $70 \%$, enquanto T6 com $68,75 \%$ e T7 obteve taxa de $67,75 \%$. Os tratamentos com menor taxa de germinação foram T10 $(11,5 \%)$ e os demais apresentaram taxas inferiores a 10\%. O tratamento $\mathrm{T} 13$ (escarificação) apresentou mais de $90 \%$ de germinação, diferentemente de Teles et al. (2000) que obtiveram índice de $71 \%$ para o mesmo tratamento. A comparação dos resultados obtidos no presente trabalho sugere que a escarificação é um tratamento indicado para a quebra de dormência de sementes de Leucaena leucocephala.

$\mathrm{Na}$ emergência de sementes de leucena o tratamento com escarificação com lima de metal (T13) apresentou 6,4 de índice de velocidade de emergência (IVE) em relação a 2,9 alcançado pelo tratamento com imersão em água quente a $80^{\circ} \mathrm{C}$, por 5 minutos (T5) (Tabela 2), discordando de Teles et al. (2000) que obtiveram o índice de velocidade de emergência de 6,3 nas sementes de leucena submetidas a imersão a $80^{\circ} \mathrm{C}$ por 5 minutos e 4,1 nas sementes submetidas a escarificação.

Tabela 2 - Análise da taxa de germinação (G\%) e índice de velocidade de emergência (IVE) de sementes de Leucaena leucocephala germinadas

\begin{tabular}{|c|c|c|c|c|c|}
\hline & $\begin{array}{c}\text { Sementes } \\
\text { Germinadas }\end{array}$ & $\mathbf{G}(\%)^{\star}$ & $\begin{array}{l}\text { Desvio } \\
\text { Padrão }\end{array}$ & IVE* $^{*}$ & Desvio \\
\hline T1 - Controle & 4 & $4^{\mathrm{c}}$ & 4,6 & $0,1^{\mathrm{c}}$ & 0,2 \\
\hline T2 - Água ambiente por $12 \mathrm{~h}$ & 9 & $9,5^{\mathrm{c}}$ & 8,8 & $0,5^{\mathrm{c}}$ & 0,5 \\
\hline T3 - Água ambiente por $24 \mathrm{~h}$ & 8 & $8,3^{c}$ & 3,7 & $0,6^{c}$ & 0,5 \\
\hline T4 - Água ambiente por $36 \mathrm{~h}$ & 6 & $6^{c}$ & 2,3 & $0,5^{\mathrm{c}}$ & 0,4 \\
\hline $\mathrm{T} 5$ - Água quente $80^{\circ} \mathrm{C}$ por $5 \mathrm{~h}$ & 86 & $89,5^{\mathrm{a}}$ & 12,6 & $2,9^{a}$ & 0,5 \\
\hline $\mathrm{T} 6$ - Água quente $80^{\circ} \mathrm{C}$ por $10 \mathrm{~min}$. & 65 & $68,8^{\mathrm{b}}$ & 8,7 & $2,2^{\text {ad }}$ & 0,6 \\
\hline $\mathrm{T} 7$ - Água quente $80^{\circ} \mathrm{C}$ por $15 \mathrm{~min}$. & 65 & $67,8^{\mathrm{b}}$ & 14,9 & $1,7^{d}$ & 0,4 \\
\hline $\mathrm{T} 8$ - Água quente $100^{\circ} \mathrm{C}$ & 67 & $70^{\mathrm{ab}}$ & 5,0 & $1,8^{\mathrm{ad}}$ & 0,2 \\
\hline T9 - Ácido Sulfúrico por 6s & 6 & $6,5^{\mathrm{c}}$ & 7,5 & $0,4^{c}$ & 0,5 \\
\hline T10 - Ácido Sulfúrico por 10s & 11 & $11,5^{\mathrm{c}}$ & 12,9 & $0,6^{\mathrm{c}}$ & 0,7 \\
\hline T11 - Soda Caustica por 6s & 8 & $8,3^{c}$ & 3,7 & $0,3^{c}$ & 0,2 \\
\hline T12 - Soda caustica por $10 \mathrm{~s}$ & 4 & $4^{c}$ & 3,3 & $0,2^{\mathrm{c}}$ & 0,2 \\
\hline T13 - Escarificação & 87 & $91^{a}$ & 3,9 & $6,4^{\text {bd }}$ & 0,3 \\
\hline
\end{tabular}

${ }^{*}$ Médias seguidas pela mesma letra na coluna não diferem entre si pelo Teste Tukey $(P<0,05)$. 
$\mathrm{Na}$ avaliação das plântulas oriundas do tratamento $\mathrm{T} 5$ (água quente a $80^{\circ} \mathrm{C}$ por 5 minutos) que compõem o grupo "A", aos 35 dias observou-se diferença significante em favor de A3, comparado com A1 e A4 (ANOVA a 1\%). A diferença se acentuou na avaliação seguinte (49 dias), com A3 atingindo altura superior em relação aos demais grupos (ANOVA a 0,1\%), essa disparidade de desenvolvimento manteve-se aproximadamente por 63 dias, apenas na última avaliação $A 1, A 2$ e $A 4$ atingiram alturas aproximadas a $\mathrm{A} 3$, confirmando a interpretação de crescimento mais rápido da parte aérea para A3 (Fig. 1).

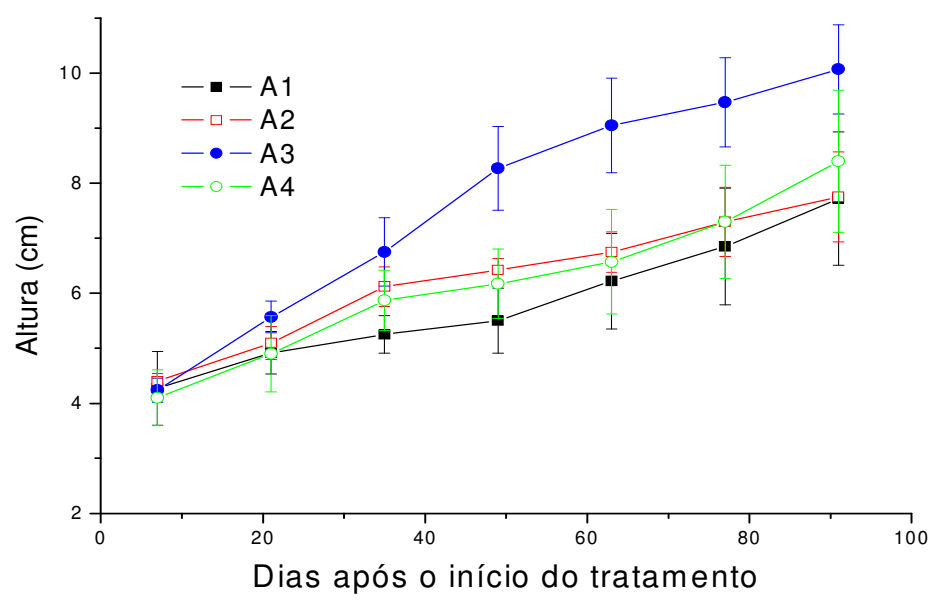

Fig. 1 - Altura das plântulas de Leucaena leucocephala (tratamento com água a $80^{\circ} \mathrm{C}$ ) em função do tempo (até 91 dias; média \pm desvio padrão). Tratamentos: A1: grupo controle com terra e serragem, A2: esterco de carneiro, A3: esterco de ave e A4: esterco de gado.

Resultado semelhante é obtido para as plântulas oriundas do tratamento T13 (escarificação com lima de metal) para a quebra de dormência (grupo "E”): aos 35 dias, o tratamento E3 mostrou 5\% de diferença na altura em relação a E1. Aos 65 dias, E3 apresentou diferença significante (a $5 \%$ ) na altura em relação aos demais grupos. No entanto, a diferença em favor de E3 deixou de ser significante nas avaliações seguintes; tais resultados na verdade sugerem que o desenvolvimento da parte aérea é mais rápido para o grupo E3 (Fig. 2) nas condições estudadas. 


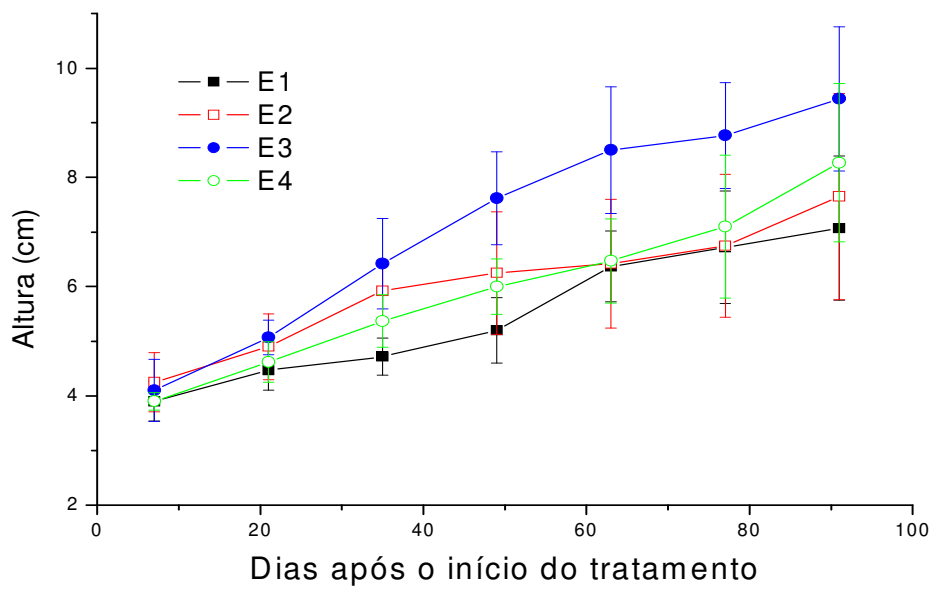

Fig. 2 - Altura das plântulas de Leucaena leucocephala (tratamento de escarificação) em função do tempo (até 91 dias; média \pm desvio padrão). Tratamentos: E1: grupo controle com terra e serragem, E2: esterco de carneiro, E3: esterco de ave e E4: esterco de gado.

Assim, analisando-se a evolução da altura das plântulas, observa-se o melhor desenvolvimento tanto para A3 quanto para E3, que atingem altura próxima a $10 \mathrm{~cm}$ após 91 dias.

Estes resultados estão de acordo com os obtidos por Lucena et al. (2006), que concluíram ser o esterco de ave mais indicado no desenvolvimento das plântulas de leucena muito mais que na germinação das sementes.
Kiehl (2001) ressalta que o esterco de ave é bastante solúvel e facilita uma rápida disponibilização, além de ser rico em nutrientes e teor de proteína. Ao somar os teores de nitrogênio $(N)$, fósforo $(P)$ e potássio (K) observou que o seu valor é duas a três vezes maior do que o encontrado nas dejeções de mamíferos, como comprovado neste estudo (Tabela 3) em que o esterco de ave demonstrou ser o melhor para o desenvolvimento da leucena.

Tabela 3 - Análise de solo dos tratamentos; 1: controle com terra e serragem, 2: esterco de carneiro, 3: esterco de ave, 4: esterco de gado

\begin{tabular}{|c|c|c|c|c|c|c|c|c|c|c|}
\hline Amostra & $P h$ & $\begin{array}{c}\mathrm{MO}^{*} \\
\mathrm{~g} / \mathrm{dm}^{3}\end{array}$ & $\begin{array}{c}P \\
\mathrm{mg} / \mathrm{dm}^{3}\end{array}$ & $K$ & Ca & $\begin{array}{c}M g \\
\mathrm{mmol} / \mathrm{dm}^{3}\end{array}$ & $\begin{array}{c}C T C^{*} \\
---\end{array}$ & $\begin{array}{l}M n \\
---\end{array}$ & $\begin{array}{c}A I \\
\mathrm{mmol} / \mathrm{dm}^{3}\end{array}$ & Zn \\
\hline 1 & 5,1 & 66 & 140 & 8,8 & 57 & 28 & 135,8 & 9,4 & - & 3,5 \\
\hline 2 & 5,6 & 71 & 230 & 17,4 & 80 & 30 & 151,4 & 11,3 & - & 5,5 \\
\hline 3 & 6,3 & 88 & 310 & 20,6 & 116 & 28 & 179,6 & 9,6 & - & 3,3 \\
\hline 4 & 5,3 & 72 & 180 & 19,4 & 58 & 31 & 140,4 & 11,4 & - & 6,9 \\
\hline
\end{tabular}

${ }^{\star}$ CTC: Capacidade de troca de cátions. MO: matéria orgânica.

Para Hoffman et al. (2001), os benefícios no uso de esterco de aves devem-se à formação física do solo e aos nutrientes, além do aumento no teor de matéria orgânica, o que melhora tanto a infiltração da água, quanto o aumento da capacidade de troca de cátions. Os resultados obtidos no presente estudo demonstraram que leucena desenvolveu-se melhor com a adubação de esterco aviário.

$$
\text { Em estudos com Leucaena }
$$
leucophala, Souza et al. (2008) constataram que o substrato com composto orgânico ao nível de adubações nitrogenadas e 
superfosfatadas resultaram diferenças significativas no início do crescimento da planta e, ao final de um ano, apresentaram altura de 2,19m e 2,5m respectivamente; porém, após quatro anos ocorreu uma redução na taxa de crescimento da altura devido à falta de adubação. Estes resultados corroboram o presente estudo, em que as plântulas também apresentaram tendência à estabilização na altura, com redução progressiva na taxa de crescimento (derivada da altura em relação ao tempo) ao longo do experimento.

Figueroa (2008), ao analisar os teores de nitrogênio, $(\mathrm{N})$ fósforo $\left(\mathrm{P}_{2} \mathrm{O}_{5}\right)$ e potássio $\left(\mathrm{K}_{2} \mathrm{O}\right)$ e a relação carbono/nitrogênio $(\mathrm{C} / \mathrm{N})$ de estercos de bovino, carneiro e ave, observou que o esterco aviário apresenta alto valor de nitrogênio, fósforo e potássio em relação aos demais tratamentos, de acordo com o que foi observado no presente estudo (Tabela 3), no qual o esterco de ave apresentou os seguintes valores (densidade expressa em $\mathrm{mg} / \mathrm{dm}_{3}$ e concentração por volume, em $\mathrm{mmol} / \mathrm{dm}_{3}$ ): fósforo, $310 \mathrm{mg} / \mathrm{dm}_{3}$; potássio; $20,6 \mathrm{mmol} / \mathrm{dm}_{3}$; matéria orgânica, $88 \mathrm{~g} / \mathrm{dm}_{3}$.

Andrade et al. (2011), ao analisar a cultura de sorgo em solos adubados com esterco de ave, gado, carneiro e sem matéria orgânica, concluiu que o sorgo desenvolveu melhor a altura no solo adubado com esterco de ave, devido aos nutrientes presentes no adubo, como verificado no presente estudo com Leucaena leucocephala quando analisados os mesmos adubos (Tabela 3).

As plântulas oriundas do tratamento T13 (escarificação com lima de metal) para a quebra de dormência, submetidas ao tratamento com esterco de ave (E3) obtiveram em média uma altura de $6,5 \mathrm{~cm}$ aos 35 dias permanecendo estabilizadas até - 73으 dia; as plântulas dos demais tratamentos estabilizaram próximo ao $73^{\circ}$ dia com a altura média de $6,5 \mathrm{~cm}$ (Fig. 2).

Conforme pode ser observado na Fig. 1 , as plântulas dos tratamentos A3 obtiveram altura superior às demais a partir do $35^{\circ}$ dia; no entanto, no $77^{\circ}$ dia, as plântulas submetidas aos outros tipos de adubação produziram resultados muito próximos ao tratamento $A 3$, não apenas na altura como também na emissão de folíolos (Fig. 3), não sendo possível apontar diferença estatisticamente significativa.

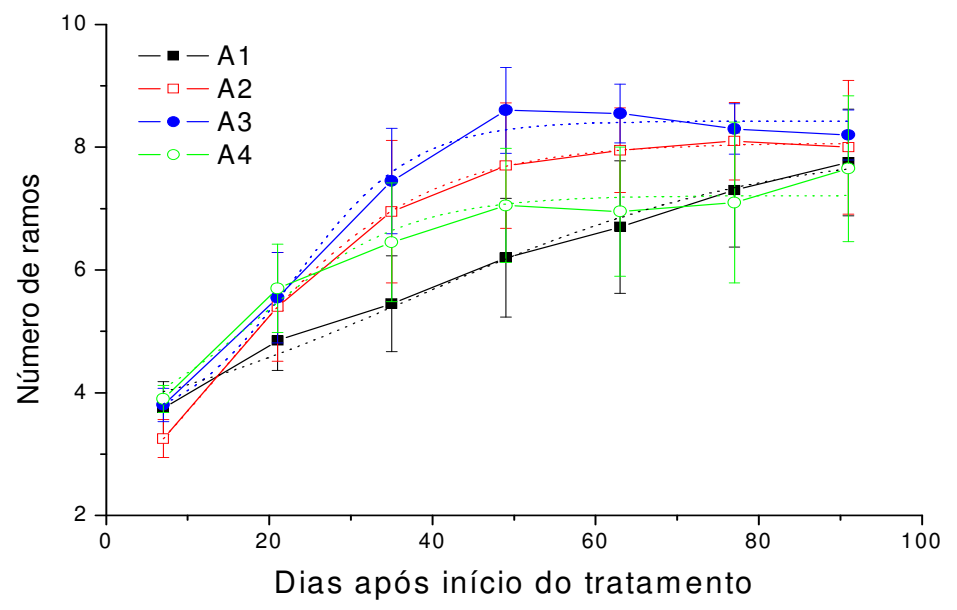

Fig. 3 - Emissão de folíolos nas plântulas de Leucaena leucocephala (tratamento com água a $80^{\circ} \mathrm{C}$ ) em função do tempo (até 91 dias; média \pm desvio padrão). Tratamentos: A1: grupo controle com terra e serragem, A2: esterco de carneiro, A3: esterco de ave e A4: esterco de gado. 
De acordo com Kiehl (2002), a baixa relação carbono/nitrogênio do esterco de ave promove maior disponibilidade de nutrientes às culturas agrícolas, em específico o nitrogênio. De fato, em muitas culturas, a disponibilidade de nitrogênio é um fator limitante, influenciando $o$ crescimento da planta mais que os demais nutrientes (BREDEMEIER; MUNDSTOCK, 2000). Os resultados obtidos sugerem que à medida que houve decréscimo do teor de nitrogênio em função de não ter sido realizada adubação posterior, as plântulas do tratamento A3 apresentaram comportamento similar às plântulas dos demais tratamentos, demonstrando a importância do nitrogênio na altura e biomassa de folíolos de leucena. Em relação à média de folíolos, plântulas originárias do tratamento E4 apresentaram melhor desenvolvimento no período do $35^{\circ}$ dia ao $49^{\circ}$ dia, conforme demonstrado na Fig. 4, e após esse período, as médias dos tratamentos E1, E2, E3, E4 apresentaram desenvolvimento semelhante estatisti-camente até 0 restante do experimento (Fig. 4). Para o desenvolvimento de mudas de Leucaena leucocephala, analisando o peso de matéria fresca dos folíolos (PMF), as plântulas do tratamento A3 (esterco de ave) e as do E3 (esterco de ave) obtiveram os maiores resultados (Tabela 4), no entanto não houve diferenças estatísticas que pudesse concluir o melhor tratamento no parâmetro peso de matéria fresca da raiz (PMR) e do caule (PMC).

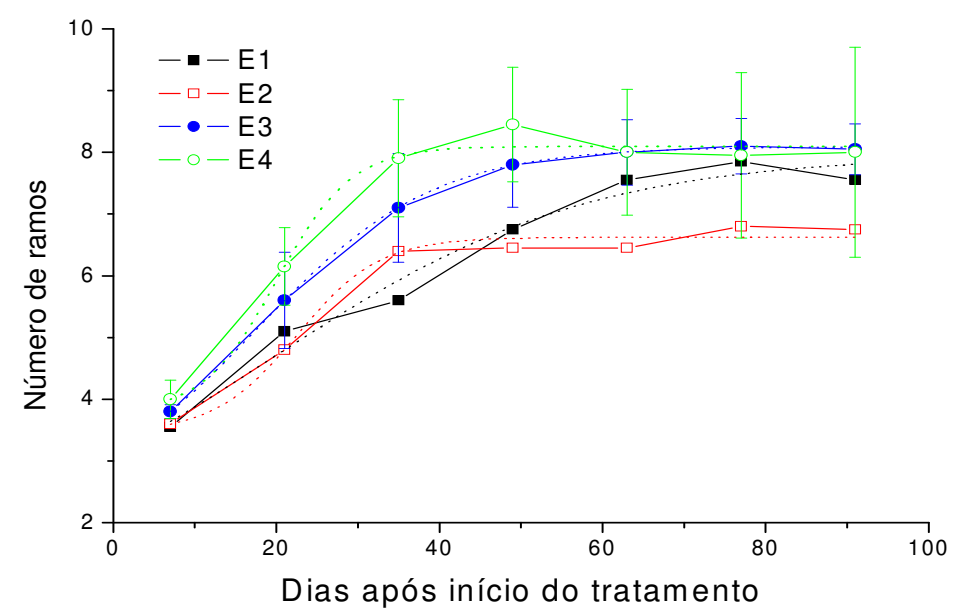

Fig. 4 - Emissão de folíolos das plântulas de Leucaena leucocephala (tratamento de escarificação) em função do tempo (até 91 dias; média \pm desvio padrão). Tratamentos: E1: grupo controle com terra e serragem, E2: esterco de carneiro, E3: esterco de ave e E4: esterco de gado.

Por outro lado, a análise do peso de matéria seca (PMS) do folíolo com pecíolo (PMS F), raiz (PMS raiz) e caule (PMS caule) (Tabelas 4 e 5 ) demonstrou resultados muito próximos ao ser analisado pelo teste estatístico, constatando que não houve um tratamento melhor para análise de peso de matéria seca, ao contrário do observado no trabalho conduzido por Lucena et al. (2006). 
Tabela 4 - Peso de matéria fresca (em gramas) de folhas (PMF), raízes (PMR) e caules (PMC) de plântulas de Leucaena leucocephala após três meses de cultivo (média \pm desvio padrão, $N=5$ ).

"A" representa tratamento com água a $80^{\circ} \mathrm{C}$; "E", escarificação; 1 : controle com terra e serragem, 2: esterco de carneiro, 3: esterco de ave, 4: esterco de gado

\begin{tabular}{cccc}
\hline Tratamento & PMF $^{*}$ & PMR & PMC \\
\hline A1 & $6,7 \pm 0,7 \mathrm{a}$ & $11,0 \pm 1,3 \mathrm{~ns}$ & $5,0 \pm 0,4 \mathrm{~ns}$ \\
A2 & $7,2 \pm 0,5_{\mathrm{ac}}$ & $9,3 \pm 1,1 \mathrm{~ns}$ & $5,6 \pm 0,7 \mathrm{~ns}$ \\
A3 & $9,2 \pm 0,7 \mathrm{~b}$ & $10,7 \pm 1,6_{\mathrm{ns}}$ & $5,8 \pm 0,4 \mathrm{~ns}$ \\
A4 & $7,0 \pm 0,9 \mathrm{ac}$ & $11,0 \pm 2,1 \mathrm{~ns}$ & $5,3 \pm 1,1 \mathrm{~ns}$ \\
E1 & $6,6 \pm 1,3_{\mathrm{a}}$ & $10,2 \pm 1,6 \mathrm{~ns}$ & $5,0 \pm 0,5 \mathrm{~ns}$ \\
E2 & $7,1 \pm 0,6 \mathrm{ac}$ & $10,5 \pm 1,2 \mathrm{~ns}$ & $5,3 \pm 0,4 \mathrm{~ns}$ \\
E3 & $8,8 \pm 1,2 \mathrm{bc}$ & $11,3 \pm 2,5 \mathrm{~ns}$ & $5,8 \pm 0,4 \mathrm{~ns}$ \\
E4 & $7,0 \pm 0,8 \mathrm{a}$ & $10,8 \pm 1,2 \mathrm{~ns}$ & $5,2 \pm 0,3 \mathrm{~ns}$ \\
\hline
\end{tabular}

*média \pm desvio padrão. Em cada coluna, letras diferentes (abc) indicam diferença significativa (ANOVA - análise de variância) com pós-teste de Tukey ao nível de 5. Letras: ns (não apresentou diferença estatística relevante) se $\mathrm{p}>0,05$.

Tabela 5 - Peso de matéria seca (em gramas) de folíolos com pecíolo (PMSF), raiz (PMSR) e caule (PMSC) de plântulas de Leucaena leucocephala após três meses de cultivo (média \pm desvio padrão, $\mathrm{N}=5$ ). " $A$ " representa tratamento com água a $80^{\circ} \mathrm{C}$; "E”, escarificação; 1 : controle com terra e serragem, 2: esterco de carneiro, 3: esterco de ave, 4: esterco de gado

\begin{tabular}{cccc}
\hline Tratamento & PMSF $^{*}$ & PMSR $^{*}$ & PMSC $^{*}$ \\
\hline A1 & $4,0 \pm 0,4 \mathrm{~ns}$ & $6,6 \pm 0,6 \mathrm{~ns}$ & $3,6 \pm 0,4 \mathrm{~ns}$ \\
A2 & $3,4 \pm 0,7 \mathrm{~ns}$ & $5,9 \pm 0,9 \mathrm{~ns}$ & $3,5 \pm 0,6 \mathrm{~ns}$ \\
A3 & $4,2 \pm 0,9 \mathrm{~ns}$ & $6,4 \pm 0,7 \mathrm{~ns}$ & $4,1 \pm 0,3 \mathrm{~ns}$ \\
A4 & $4,1 \pm 0,4 \mathrm{~ns}$ & $6,5 \pm 1,0 \mathrm{~ns}$ & $3,6 \pm 0,6 \mathrm{~ns}$ \\
E1 & $3,4 \pm 0,7 \mathrm{~ns}$ & $6,1 \pm 0,6 \mathrm{~ns}$ & $3,3 \pm 0,6 \mathrm{~ns}$ \\
E2 & $3,9 \pm 0,4 \mathrm{~ns}$ & $6,1 \pm 0,4 \mathrm{~ns}$ & $3,9 \pm 0,6 \mathrm{~ns}$ \\
E3 & $4,1 \pm 0,5 \mathrm{~ns}$ & $6,5 \pm 1,1 \mathrm{~ns}$ & $3,7 \pm 0,6 \mathrm{~ns}$ \\
E4 & $3,7 \pm 0,6 \mathrm{~ns}$ & $6,0 \pm 1,4 \mathrm{~ns}$ & $3,7 \pm 0,5 \mathrm{~ns}$ \\
\hline${ }^{*}$ Letras: ns (não apresentou diferença estatística relevante) se p>0,05.
\end{tabular}

Na maioria dos parâmetros analisados, as plântulas submetidas ao tratamento A3 apresentaram resultados superiores em relação ao tratamento E3 ao longo do experimento, a partir do $40^{\circ}$ dia. No entanto, ao término do estudo, não foi possível apontar ganhos percentuais, uma vez que os dois tratamentos tendem à estabilização em valores semelhantes (sem diferença estatística significativa).

\section{CONCLUSÃO}

No que se refere à quebra de dormência das sementes de leucena, o presente estudo mostra que os tratamentos mais eficientes foram T5 (sementes submetidas à água quente a $80^{\circ} \mathrm{C}$ por 5 minutos) e T13 (sementes submetidas à escarificação com lima de metal). No entanto, quando se considera 0 desenvolvimento das mudas ao final do experimento, as plântulas oriundas desses dois tratamentos apresentam resultados semelhantes e é o tipo de substrato (adubação orgânica) que gera diferenças significantes nos parâmetros avaliados, com os resultados indicando que o esterco de ave é o melhor adubo orgânico para Leucaena leucocephala (Lam.) de Wit.

\section{REFERÊNCIAS}

ANDRADE, A. R. S.; MACHADO, C. B.; 
VILELA, E. L.; CAMÊLO, D. L.; SILVA, L. C. C. Desenvolvimento da cultura do sorgo em um latossolo amarelo submetido à adubação orgânica. Revista Brasileira de Tecnologia Aplicada nas Ciências Agrárias, v. 4, n. 2, p. 137-151, 2011.

BENICASA, M. M. P. Análise de crescimento de plantas: noções básicas. Jaboticabal. FUNEP, p. 42, 2004.

BREDEMEIER, C.; MUNDSTOCK, C. M. Regulação da Absorção e Assimilação do Nitrogênio nas Plantas. Ciência Rural, v. 30, n. 2, p. 365-372, 2000.

CARVALHO, N. M.; NAKAGAWA, J. Sementes: ciências e tecnologia e produção. 4 ed. Jaboticabal, FUNEP, 2000.

DEMINICIS, B. B., ALMEIDA, J. C. C., BLUME, M. C.; ARAÚJO, S. A. C.; VIEIRA, H. D. Poder germinativo de sementes de Leucena leucocephala. PUBVET, v. 2, n. 12, 2008.

EL- BEDAWY, T. M.; ABD- EL- SAMMAD, A. M.; SAADA, M. Y.; ABD- EL- FATTAH, S. M. Effect of sodium acetate treatment on metabolism of mimosine and dihyydroxy pyridine of Leucena leaves fed to gosts. Egyptian Journal of Nutriton and Feeds, v. 2, p. 67-77, 1999.

FIGUEROA, E. A. Efeito imediato e residual de esterco de ave poedeira em culturas de grãos. Passo Fundo - Rio Grande do Sul, 106p. Dissertação (Mestrado em Agronomia) - Universidade de Passo Fundo, 2008.

HOFFMANN, I.; GERLING, D.; KYIOGWOM, U. B.; MANÉ-BIELFELDT, A. Farmers management strategies to maintain soil fertility in a remote área in northwest Nigeria. Agriculture Ecosystems Environment, v. 86, p. 263-275. 2001.

KIEHL, J. C. Produção de composto orgânico e vermicomposto. Informe Agropecuário, Belo Horizonte, v. 22, p. 4042, 2001.

KIEHL, E. J. Manual de Compostagem: Maturação e Qualidade do Composto. 3. ed. Piracicaba, p. 171, 2002.

LIMA, J. A.; EVANGELISTA, A. R. Leucena (Leucaena leucocephala). Boletim de extensão. UFLA - Lavras - MG, 2006. Disponível em http://editora.ufla.br/Boletim/pdfextensao/bol _64.pdf Acesso em 2006.

LUCENA, A. M. A.; COSTA, F. X.; SILVA, H.; GUERRA, H. O. C. Germinação de essências florestais em substratos fertilizados com matéria orgânica. Revista de Biologia e Ciências da Terra, v. 4, n. 2, 2004.

LUCENA, A. M. A.; GUERRA, H. O. C.; CHAVES, L. H. G. Desenvolvimento de mudas de Leucena e Flamboyant em diferentes composições de substratos. Revista Verde, v. 1, n. 2, p. 16- 23, 2006.

NAGUIRE, J. D. Speed of germination - aid in selection and evaluation for seedling emergence and vigor. Grop. Science, Madison, v. 2, n. 1, p. 176-177, 1962.

MALUF, A. M.; PISCIOTTANO-EREIO, W. A. Secagem e armazenamento de sementes de Cambuci. Pesquisa Agropecuária Brasileira, Brasília, v. 40, n. 7, p. 707-714, 2005.

MENDES, S. S.; Qualidade sanitária e fisiológica de sementes de Leucena (Leucaena leucocephala (Lam.) de Wit.): uma legumionosa de importância para sistemas agrícolas do nordeste. São Cristovão, SE. p. 48. Dissertação (Mestrado em Agroecossistemas) Universidade Federal de Sergipe, 2006.

NAKAGAWA, J. Testes de vigor baseados na avaliação das plântulas. In: 
KRZYZANOSKI, F. C.; VIEIRA, R. D.; SOUZA, C. M.; SILVA, J. A. A.; FERREIRA, FRANÇA NETO, J. B. (Ed.). Vigor em R. L. C.; SANTOS, E. S.; MEUNIER, I. J.; sementes: conceitos e testes. Londrina: FERRAZ, I. Avaliação do crescimento em ABRATES, p. 2.1-2.24, 1999.

OLIVEIRA, A. B.; MEDEIROS FILHO, S. Influência de tratamentos pré - germinativos, temperatura e luminosidade na germinação de sementes de leucena. Revista Brasileira de Ciências Agrárias, v. 2, n. 4, p. 268-274, 2007.

PRATES, H. T.; PAES, J. M. V.; PIRES, N. M.; FILHO, I. A. P.; MAGALHÃES, P. C. Efeitos do extrato aquoso de leucena na germinação e no desenvolvimento do milho. Pesquisa Agropecuária Brasileira, v. 35, n. 5, p. 909-914, 2000.

SOUZA-FILHO, A. P.; RODRIGUES, L. R. A.; RODRIGUES, T. J. D. Efeitos do potencial alelopático de três leguminosas forrageiras sobre três invasoras de pastagens. Pesquisa Agropecuária Brasileira, v. 32, n. 2, p. 165-170, 1997.

SOUSA, F. B. Leucena: Produção e Manejo no Nordeste Brasileiro. Circular técnica, p. 20, 2005. altura de Leucaena leucocephala (Lam.) de Wit., no agreste de Pernambuco. Revista Brasileira de Ciências Agrária, v. 3, n. 3, p. 260-266, 2008.

SOUZA, E. R. B.; ZAGO, R.; GARCIA, J.; FARIAS, J. G.; CARVALHO, E. M. S.; BARROSO, M. R. Efeito de métodos de escarificação do tegumento em sementes de Leucaena diversifolia L. Pesquisa Agropecuária Tropical, v. 37, n. 3, p. 142146, 2007.

TEles, M. M., ALVES, A. A., BeZERRA, A. M. E.; Métodos para quebra de dormência em Sementes de Leucena Leucaena leucocephala (Lam.) de Wit. Revista Brasileira de Zootecnia, v. 29, n. 2, p. 387391, 2000.

VAN RAIJ, B.; ANDRADE, J. C.; CANTERELLA, H. QUAGGIO, J. A. Análise Química para Avaliação da Fertilidade de Solos Tropicais. Campinas: Instituto Agronômico, 2001. 